\title{
Increased expression of the WNT antagonist SFRP-1 in glaucoma elevates intraocular pressure
}

\author{
Wan-Heng Wang, ${ }^{1}$ Loretta G. McNatt, ${ }^{1}$ lok-Hou Pang, ${ }^{1} \mathrm{~J}$. Cameron Millar, ${ }^{1}$ \\ Peggy E. Hellberg, ${ }^{1}$ Mark H. Hellberg, ${ }^{1}$ H. Thomas Steely, ${ }^{1}$ Jeffrey S. Rubin, ${ }^{2}$ \\ John H. Fingert, ${ }^{3}$ Val C. Sheffield, ${ }^{4,5}$ Edwin M. Stone, ${ }^{3,4}$ and Abbot F. Clark ${ }^{1}$

\begin{abstract}
${ }^{1}$ Alcon Research Ltd., Fort Worth, Texas, USA. ${ }^{2}$ Laboratory of Cellular and Molecular Biology, National Cancer Institute, NIH, Bethesda, Maryland, USA. ${ }^{3}$ Department of Ophthalmology and Visual Sciences, University of lowa Carver College of Medicine, lowa City, lowa, USA.

${ }^{4}$ Howard Hughes Medical Institute, lowa City, lowa, USA. ${ }^{5}$ Department of Pediatrics, University of lowa Carver College of Medicine, Iowa City, Iowa, USA.
\end{abstract}

\begin{abstract}
Elevated intraocular pressure (IOP) is the principal risk factor for glaucoma and results from excessive impedance of the fluid outflow from the eye. This abnormality likely originates from outflow pathway tissues such as the trabecular meshwork (TM), but the associated molecular etiology is poorly understood. We discovered what we believe to be a novel role for secreted frizzled-related protein-1 (sFRP-1), an antagonist of Wnt signaling, in regulating IOP. sFRP1 was overexpressed in human glaucomatous TM cells. Genes involved in the Wnt signaling pathway were expressed in cultured TM cells and human TM tissues. Addition of recombinant sFRP-1 to ex vivo perfusion-cultured human eyes decreased outflow facility, concomitant with reduced levels of $\beta$-catenin, the Wnt signaling mediator, in the TM. Intravitreal injection of an adenoviral vector encoding $s F R P 1$ in mice produced a titer-dependent increase in IOP. Five days after vector injection, IOP increased 2 fold, which was significantly reduced by topical ocular administration of an inhibitor of a downstream suppressor of Wnt signaling. Thus, these data indicate that increased expression of $s F R P 1$ in the TM appears to be responsible for elevated IOP in glaucoma and restoring Wnt signaling in the TM may be a novel disease intervention strategy for treating glaucoma.
\end{abstract}

\section{Introduction}

Glaucoma is a major cause of irreversible visual impairment and blindness in the world $(1,2)$. Approximately 70 million individuals have this disease, although more than half of the patients are unaware of their sight-threatening conditions (1). Glaucoma is a heterogeneous group of optic neuropathies, and primary openangle glaucoma (POAG) is the most prevalent form of glaucoma in Western populations (3). Elevated intraocular pressure (IOP) is the principal causative risk factor responsible for both the development (4) and progression $(5,6)$ of glaucoma.

IOP is regulated by a delicate equilibrium between the production and outflow rates of aqueous humor, the clear fluid that is responsible for the metabolic homeostasis in the anterior segment of the eye. Glaucomatous ocular hypertension results from an excessive impedance of the outflow of aqueous humor, likely a consequence of functional abnormalities in outflow pathway tissues, such as the trabecular meshwork (TM) (6-9). However, the related molecular etiology for glaucomatous damage to the outflow pathway is poorly understood. Despite evidence that inheritance clearly plays a role in glaucoma, the identified glaucoma loci and several glaucoma genes account for only a small fraction of patients with this disorder (10-12).

Evaluation of differential gene and protein expression between normal and glaucomatous TM cells and tissues is one approach

Nonstandard abbreviations used: BMP, bone morphogenic protein; $\mathrm{CB}$, ciliary body; FZD, frizzled; GSK-3, glycogen synthase kinase-3; IOP, intraocular pressure; RDD, RNA differential display; sFRP, secreted frizzled-related protein; TM, trabecular meshwork.

Conflict of interest: W.-H. Wang, L.G. McNatt, I.-H. Pang, J.C. Millar, P.E. Hellberg, M.H. Hellberg, H.T. Steely, and A.F. Clark are employees of Alcon Research Ltd. Citation for this article: J. Clin. Invest. 118:1056-1064 (2008). doi:10.1172/JCI33871. used to identify pathogenic pathways involved in glaucoma. Expression of various gene products was found to be increased in glaucomatous TM tissues and cells, including E-Selectin (ELAM-1) $(13,14)$ and cochlin $(15,16)$. One key challenge remains as to whether these differences play an essential role in the pathogenic process or are merely associated secondarily with glaucoma. To resolve this question, it is necessary to show that altered expression of the target gene causes glaucoma-like phenotypical changes in an appropriate study model. For this purpose, we used perfusioncultured human ocular anterior segments and viral vector transgene expression in the mouse eye (17) to confirm differentially expressed genes as meaningful glaucoma targets.

In the present study, we found that secreted frizzled-related protein-1 (sFRP-1), an antagonist of the Wnt signaling pathway $(18,19)$, was differentially expressed in glaucomatous human TM cells compared with normal human TM cells. We further showed that human TM cells possess a functional Wnt signaling pathway, and that the addition of recombinant sFRP-1 to ex vivo perfusion-cultured anterior segments of human eyes decreased aqueous humor outflow facility. In addition, we observed that overexpression of sFRP- 1 by a viral vector in mouse eyes led to elevated IOP, a characteristic phenotype of glaucoma. Topical ocular administration of an inhibitor of glycogen synthase kinase-3 (GSK-3), a downstream suppressor of Wnt signaling, lowered IOP in sFRP-1-induced ocular hypertensive eyes, further supporting the role of Wnt signaling in regulating IOP.

\section{Results}

Identification of SFRP-1 differentially expressed in glaucomatous TM cells. Approximately 2,400 PCR products of 120-650 base pairs in length from cDNAs of cultured TM cells derived from normal and 


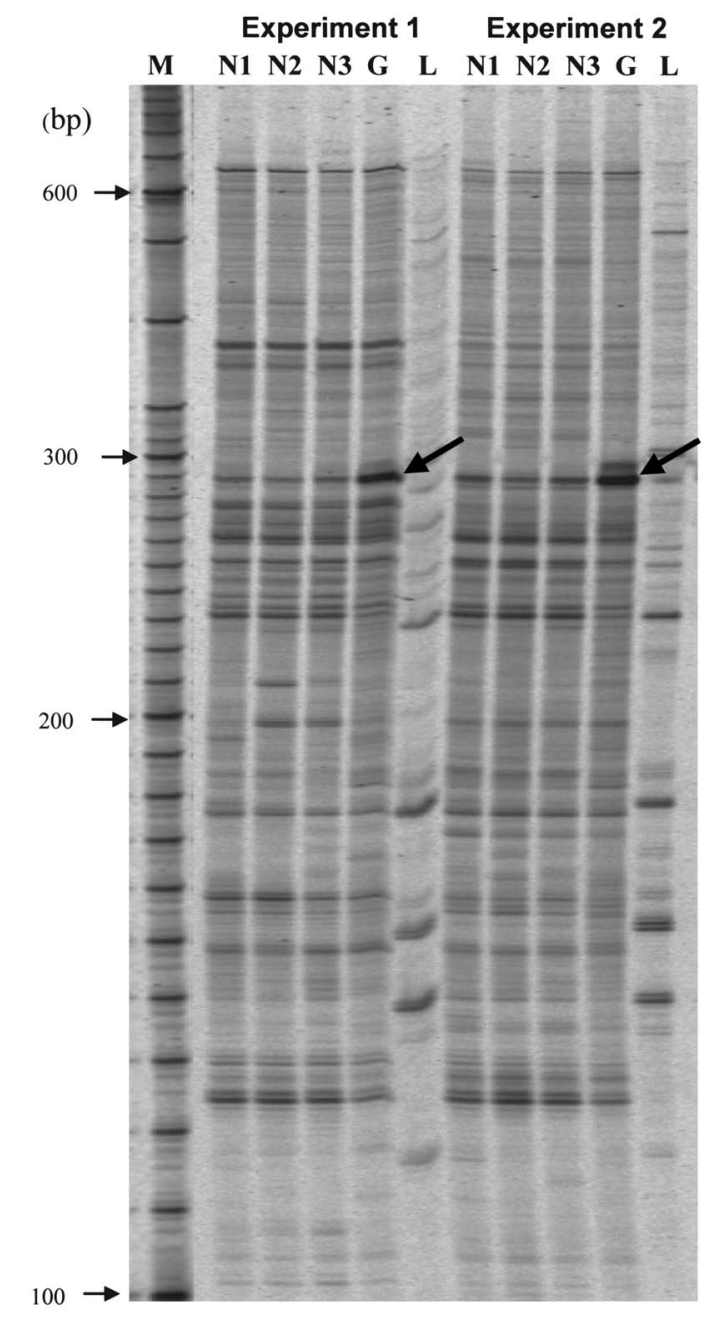

glaucomatous donors were compared using RNA differential display (RDD). Autoradiographs of 2 RDD studies using HAP1 and $\mathrm{H}-\mathrm{T} 11 \mathrm{~A}$ primers showed that 1 band appeared to be greatly increased in the glaucomatous TM cell line compared with the normal TM cell line (Figure 1, bold arrows). PCR reamplification and sequence of the corresponding band resulted in a 240-base pair sequence that was identical to the human sFRP1 mRNA (GenBank accession number NM_003012).

Confirmation of differential sFRP1 expression in glaucomatous TM cells. To confirm the RDD discovery of differentially expressed sFRP1 in glaucomatous TM cells, quantitative RT-PCR was used to quantify sFRP1 expression in TM cell lines derived from 6 closely age-matched pairs of normal and glaucomatous donors. Levels of sFRP1 mRNA were elevated in all 6 glaucomatous cell lines compared with their respective controls with a 4.5 -fold mean increase $(P<0.01)$ (Figure 2A). Similar results were obtained by Northern blot analysis (data not shown). In addition, ELISA evaluation demonstrated that sFRP-1 protein was also significantly elevated $(49.3 \% ; P<0.05)$ in homogenates of glaucomatous TM cells $(19.6 \pm 3.2 \mathrm{ng} / \mathrm{mg}$ protein, mean $\pm \mathrm{SEM} ; n=10)$ compared with normal TM cells $(12.5 \pm 1.5 \mathrm{ng} / \mathrm{mg}$ protein; $n=13)$ (Figure $2 \mathrm{~B}$ ).

Expression of genes involved in Wnt signaling in TM. SFRP-1 is an antagonist of Wnt signaling. To determine whether Wnt signaling pathway genes are expressed in the TM, we examined cultured TM

\section{Figure 1}

Identification of SFRP1 differential expression in glaucomatous TM cells. RDD of normal TM cells compared with glaucomatous TM cells. M, molecular size markers; N1-N3, normal TM cells (NTM70A); G, glaucoma TM cells (GTM29A); L, control sample derived from human liver. Bold arrows indicate a differential display band in the glaucoma TM cells. Experiments 1 and 2 represent independent $P C R$ reactions, which used the same samples and primers (HAP1/T11A). The DNA sequence of the differentially expressed cDNA fragment in glaucomatous TM cells is identical to SFRP1 (GenBank accession number NM_003012).

cells and TM tissues from normal donors using Affymetrix gene microarrays and RT-PCR followed by sequence validation of PCR products. Table 1 is a summary of key members of Wnt signaling pathway that were detected in TM cells and/or tissues. These include mRNAs for several Wnt genes (WNT2b, WNT5a, and WNT5b), Wnt receptors (frizzled [FZD] genes - FZD1, FZD2, FZD3, FZD4, FZD6, FZD7, and FZD8), and Wnt antagonists (SFRP1 and SFRP-4). The Wnt coreceptors, $L R P 5$ and $L R P 6$, were detected as well. TM cells also expressed genes for the key Wnt intermediate signaling molecules, $\beta$-catenin (CTNNB1), adenomatous polyposis coli (APC), disheveled $(D V L)$, Axin 2, and GSK-3 $\beta$, as well as transcription factors (TCF3, TCF4, and TCF7) that mediate Wnt-regulated gene expression. Other Wnt members (WNT1, WNT3, WNT4, WNT6, WNT7, WNT8, WNT9, WNT10, WNT11, and WNT16) and FZD members (FZD5, FZD9, and FZD10) were undetectable (absent) in our microarray analysis.

The presence of mRNAs for many of these genes in the TM cells was confirmed by RT-PCR with sequencing validation. Since there are at least $19 \mathrm{Wnt}$ and 10 FZD members, for a quick validation of the microarray results, 2 sets of common primers with mixed base pairs to target WNT1, -2, -5, -7, and -8, and FZD1, FZD2, FZD3, FZD5, FZD7, and FZD9, respectively, were designed (Table 2). RT-PCR followed by sequence validation of the PCR products identified the expression of 2 Wnt members (WNT2 $b$ and WNT5a) and 3 Wnt receptors (FZD1, FZD2, and FZD7) in TM cells (Table 1).

Effects of sFRP-1 in perfusion-cultured buman eyes. The expression of sFRP1 and other genes related to Wnt signaling in the adult TM suggests that this pathway may be involved in normal TM functions. Since a major function of the TM is regulation of aqueous humor outflow and thus IOP, we determined whether administration of sFRP-1 could change these parameters. The ex vivo human ocular perfusion organ culture was used to evaluate whether sFRP-1 has a direct effect on human aqueous outflow and Wnt signaling through modulating $\beta$-catenin levels in TM tissues. Anterior segments from 4 pairs of human donor eyes were perfused under constant hydrostatic pressure of $12.5 \mathrm{mmHg}$ and the outflow facility was monitored. After equilibration for 1 to $2 \mathrm{~d}$, the basal outflow rate of the eyes stabilized to $2.9 \pm 0.4 \mu \mathrm{l} / \mathrm{min}$ (mean $\pm \mathrm{SEM} ; n=8$ ). One eye of each pair was then randomly assigned to be perfused with medium, while the contralateral eye was perfused with medium containing recombinant human sFRP-1 $(10 \mu \mathrm{g} / \mathrm{ml})$. The outflow rate was reduced in eyes receiving sFRP-1 compared with control eyes, starting $1 \mathrm{~d}$ after treatment. The reduction became statistically significant at days 3 and $4(P<0.05)$, with a $55 \%$ reduction at day 4 (Figure $3 \mathrm{~A})$.

There was no detectable sFRP-1 protein by Western blot analysis of the TM and ciliary body (CB) tissues in the control perfused anterior segments. However, sFRP-1 was clearly detected in these 2 tissues perfused with recombinant sFRP-1, confirming that the sFRP-1 recombinant protein perfused into organ cultures was stable and accessible to the TM and CB (Figure 3B). Treatment 
A

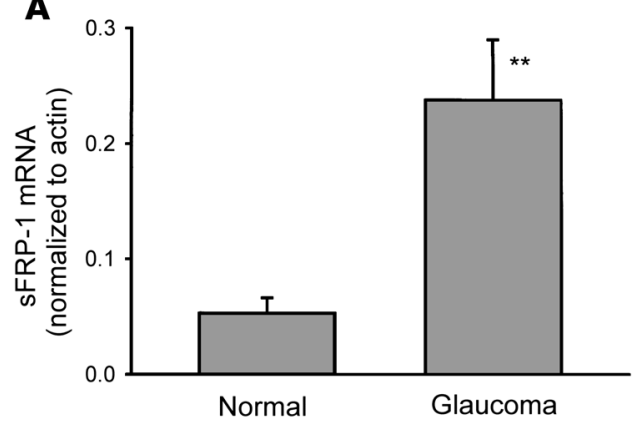

B

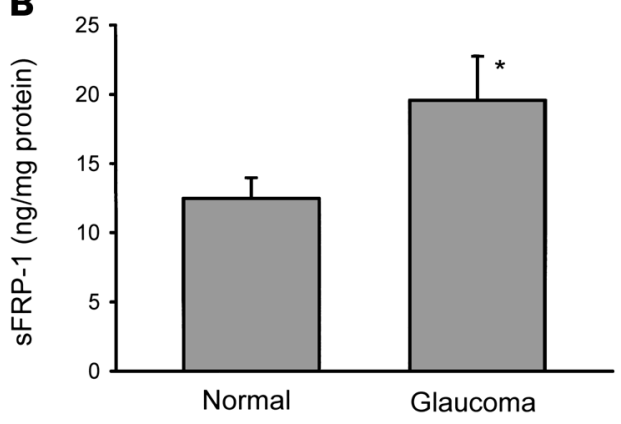

with sFRP-1 also decreased protein levels of cytosolic $\beta$-catenin, a key intermediate in the canonical Wnt signaling pathway, in both tissues (Figure 3B). The $\beta$-catenin immunoblot results were corroborated by ELISA measurements. In the sFRP-1-treated human eyes, $\beta$-catenin protein levels were significantly reduced by $41 \%(n=4 ; P<0.01)$ in the TM tissue and by $55 \%(P<0.01)$ in the CB (Figure $3 \mathrm{C})$. These data indicate that both the TM and $\mathrm{CB}$ have a functional Wnt/ $\beta$-catenin signaling pathway that is negatively regulated by the WNT antagonist sFRP-1. These cellular changes are associated with a reduced outflow facility in perfused human eyes, which would correspond to an elevated IOP, an important glaucoma phenotype.

In vivo effects of sFRP-1. The in vivo effect of sFRP-1 on IOP was studied in $\mathrm{BALB} / \mathrm{c}$ mice that received intravitreal injections of an adenoviral vector encoding sFRP-1 (Ad5.sFRP-1) $\left(3 \times 10^{7} \mathrm{PFU} /\right.$ eye). As a control, Ad5.Null $\left(3 \times 10^{7} \mathrm{PFU} /\right.$ eye $)$ was also injected intravitreally. Baseline IOP values of the injected and noninjected eyes were similar: Ad5.sFRP-1, $11.4 \pm 0.1 \mathrm{mmHg}$ (mean \pm SEM; $n=6)$; Ad5.Null, $11.7 \pm 0.4 \mathrm{mmHg}(n=6)$; and noninjected eyes, $11.6 \pm 0.2 \mathrm{mmHg}(n=12)$. Five days after injection, Ad5.sFRP-1 produced a highly significant $(P<0.001)$ pressure increase. The IOP peaked at $26.5 \pm 2.9 \mathrm{mmHg}$, more than doubling the pretreatment value, while the IOPs of noninjected or Ad5.Null-injected eyes remained unchanged. The significant elevation in IOP in the vector-treated eyes persisted until the study was stopped at day 11 (Figure 4A). In this study, there was a slight but statistically insignificant decrease in IOP in the Ad5.sFRP-1-injected eyes after day 5. Because this reduction was not observed in other studies (Figure 5 and unpublished observations), it was likely a result of biological and technical variability.

The magnitude of IOP changes induced by Ad5.sFRP-1 was dependent on the amount of vector injected. In a separate study, different titers of Ad5.sFRP-1, ranging from $2 \times 10^{6}$ to $5 \times 10^{7}$ $\mathrm{PFU} /$ eye, were injected. As a control, Ad5.GFP $\left(5 \times 10^{7} \mathrm{PFU} /\right.$ eye $)$ was also injected intravitreally. Mouse eyes in the Ad5.GFP-inject-

\section{Figure 2}

Confirmation of sFRP-1 differential expression in glaucomatous TM cells. (A) Quantitative RT-PCR quantitation of sFRP-1 expression in 6 age-matched pairs of normal and glaucomatous TM cell lines. (B) ELISA analysis of SFRP-1 protein levels in 13 normal and 10 glaucomatous TM cell lines. Data are shown as mean \pm SEM. ${ }^{*} P<0.05$; ${ }^{\star \star} P<0.01$.

ed group expressed GFP as demonstrated by green fluorescence in the eye, but Ad5.GFP did not significantly alter IOP (data not shown). In contrast, Ad5.sFRP-1 injection produced a titer-dependent increase in IOP. Four days after injection, the higher titers of Ad5.sFRP- $1\left(1 \times 10^{7}\right.$ and $5 \times 10^{7} \mathrm{PFU} /$ eye $)$ caused significant IOP elevations to $24.6 \pm 5.4(n=3)$ and $23.1 \pm 5.1 \mathrm{mmHg}$, respectively $\left(P<0.01\right.$ vs. the noninjected eyes), whereas the lower titer $\left(2 \times 10^{6}\right.$ PFU/eye) had no effect on IOP (Figure 4B).

Six days after injection of the viral vector, expression of $s F R P 1$ was detected by quantitative RT-PCR analysis in all eyes injected with Ad5.sFRP-1, whereas no endogenous mouse sFRP1 expression was detected in control noninjected eyes, reflecting specificity of the primer/probe set designed for human $s F R P 1$. Mouse $s F R P 1$, which has $72 \%$ sequence homology with human $s F R P 1$, was detected in these samples by a separate mouse microarray study (data not shown). The levels of human sFRP1 mRNA increased in a titer-dependent manner, in that more sFRP1 mRNA was observed in eyes injected with higher titers of Ad5.sFRP-1 (Figure 4C). There was a positive correlation between $s F R P 1$ expression and IOP in these animals (Figure 4D). The measured sFRP1 mRNA signal in Ad5.sFRP-1-injected eyes was not the result of Ad5.sFRP1 viral DNA contamination, because mixing cDNA made from homogenates of the noninjected eyes with Ad5.sFRP-1 $\left(5 \times 10^{7}\right.$ PFU) did not generate PCR-measurable sFRP-1 expression in the cDNA (data not shown).

sFRP-1, by inhibiting Wnt, activates GSK-3 $\beta$-mediated phosphorylation of $\beta$-catenin, an important constituent of the canonical Wnt signaling pathway. Phosphorylation marks $\beta$-catenin for ubiquitination and subsequent proteolysis by the proteasome. Inhibitors of GSK-3 $\beta$ suppress phosphorylation of $\beta$-catenin and prevent its degradation, and therefore, could functionally antagonize the sFRP-1 effect. This concept of blocking the effect of sFRP1 with inhibitors of GSK-3 $\beta$ was tested in ocular hypertensive rodents using a potent GSK-3 $\alpha$ and $-3 \beta$ inhibitor, $N$ - $(5$-phenyl- $1 \mathrm{H}$ pyrazolo[3,4-C]pyridazino-3 yl)-4-morpholine butanamide (Compound 12 described in ref. 20). Twice daily topical ocular administration of Compound 12 (1\% wt/vol suspension), starting at 3 days after intravitreal injection of Ad5.sFRP-1 (3 $\times 10^{7}$ PFU/eye), significantly reduced the elevated IOP when compared with vehicle treated Ad5.sFRP-1-injected eyes (Figure 5). The reduction in IOP persisted for at least 2 additional days beyond the termination of drug administration at day 5. Eventually, at day 10, 5 days after dosing was stopped, the 2 groups had similar IOP values. Careful, twice daily examinations by a masked researcher indicated that Compound 12 did not produce any observable ocular (assessed using a hand-held ophthalmoscope) or systemic (judged by normal gross appearance and behavior) untoward effects. Reduction of sFRP1induced ocular hypertension by a GSK-3 inhibitor strongly implicates canonical Wnt signaling in this glaucoma phenotype.

\section{Discussion}

In this report we showed that sFRP1 mRNA expression determined by RDD was elevated in cultured human TM cells derived from 


\section{Table 1}

Wht signaling pathway genes expressed in human TM cells and tissues

\begin{tabular}{lc} 
Gene names & Accession ID \\
WNT2b & NM_024494.1 \\
WNT5a & NM_003392.1 \\
WNT5b & NM_030775.1 \\
FZD1 & AF072872 \\
FZD2 & L37882 \\
FZD3 & NM_017412.2 \\
FZD4 & NM_012193.1 \\
FZD6 & NM_003506.1 \\
FZD7 & NM_003507.1 \\
FZD8 & AW340311 \\
SFRP1 & NM_003012.2 \\
SFRP-4 & AW089415 \\
CTNNB1 & NM_001904.1 \\
APC & S67788 \\
GSK33 & Al431788 \\
AXIN2 & BF684446 \\
DVL1 & AF006011 \\
DVL3 & NM_004423.2 \\
TCF3 & M31523 \\
TCF4 & NM_003199.1 \\
TCF7 & NM_003202.1 \\
LRP5 & AB017498 \\
LRP6 & AV725248 \\
& \\
\hline
\end{tabular}

$\begin{array}{cc}\text { Microarray expression detection } \\ \text { TM cell } & \text { TM tissue } \\ + & + \\ + & - \\ + & - \\ + & - \\ + & + \\ - & + \\ + & - \\ + & - \\ + & - \\ + & + \\ + & + \\ + & - \\ + & - \\ + & + \\ + & + \\ + & + \\ + & + \\ + & + \\ + & - \\ + & + \\ + & + \\ + & + \\ + & +\end{array}$

RT-PCR/Sequence validation TM cells

+
+
-
+
+
-
NT
NT
+
NT
+
NT
NT
NT
NT
NT
NT
NT
NT
NT
NT
NT
NT

Studies were performed as described in Methods. TM cell data was obtained from U133 Plus2.0 chips in triplicates. TM tissue data was from U133A/B chips in 1 study. Microarray expression detection calls (+, presence; -, absence) were determined statistically by the Affymetrix MAS5.1 software based on signal intensities and variances. Other Wnt members (Wnt1, Wnt3, Wnt4, Wnt6, Wnt7, Wnt8, Wnt9, Wnt10, Wnt11, and Wnt 16) and FZD members (FZD5, FZD9, and FZD10) were absent (undetectable) in both TM cell and tissue by the microarray analysis. RT-PCR/sequence validation indicates the presence or absence of the nucleotide sequence of the specified gene in the RT-PCR product. NT, not tested.

a glaucoma patient. This finding was confirmed by quantitative RT-PCR evaluation in TM cells derived from 6 glaucoma donors and 6 age-matched normal donors. The sFRP-1 protein levels, as measured by ELISA, were also elevated in 10 glaucomatous human TM cell lines compared with 13 normal TM cell lines.
In addition to sFRP-1, various components of the Wnt signaling pathway, including several Wnt proteins, their receptors (FZD proteins and LRP5/6), antagonists (sFRP proteins), and intracellular molecules responsible for Wnt signal transduction were detected in cultured human TM cells as well as human TM tissues. These find-

\section{Table 2}

Primers and probes used in current study

\begin{tabular}{|c|c|c|}
\hline Gene targets & Primers/probes & Sequences \\
\hline \multirow[t]{3}{*}{ sFRP1 } & Forward & GAGTCCGTGGTTGCCCTAGA \\
\hline & Reverse & GCAATCAAGTTCAAAGGAAATGTTT \\
\hline & Probe & FAM-CCCCTAGCAAAACTCACAGAGCTTTCCGT-TAMARA \\
\hline \multirow[t]{2}{*}{ WNT1, $-2,-5,-7$, and -8} & Forward & $\mathrm{G}(\mathrm{G} / \mathrm{T} / \mathrm{C} / \mathrm{A}) \mathrm{GGCTGC}(\mathrm{A} / \mathrm{G} / \mathrm{T})(\mathrm{G} / \mathrm{C})(\mathrm{C} / \mathrm{T}) \mathrm{G}(\mathrm{A} / \mathrm{C})(\mathrm{C} / \mathrm{T})(\mathrm{A} / \mathrm{G}) \mathrm{A}(\mathrm{C} / \mathrm{T})(\mathrm{A} / \mathrm{G}) \mathrm{T}(\mathrm{T} / \mathrm{C} / \mathrm{G})(\mathrm{G} / \mathrm{C})(\mathrm{A} / \mathrm{G}) \mathrm{CT}$ \\
\hline & Reverse & $(\mathrm{G} / \mathrm{C})(\mathrm{A} / \mathrm{T}) \mathrm{GCC}(\mathrm{G} / \mathrm{T} / \mathrm{A})(\mathrm{G} / \mathrm{C})(\mathrm{A} / \mathrm{T}) \mathrm{CA}(\mathrm{C} / \mathrm{T})(\mathrm{C} / \mathrm{G}) \mathrm{CC}(\mathrm{G} / \mathrm{A}) \mathrm{TGGCACTT}$ \\
\hline \multirow[t]{2}{*}{$F Z D 1,-2,-3,-5,-7$, and -9} & Forward & ATGGCCAGCTC(C/G)(A/C)TCTGGTGGGT \\
\hline & Reverse & CTCCAGCTT(C/T/G)TC(G/C/T)GT(C/G)TTGGTGC \\
\hline \multirow[t]{2}{*}{ WNT2b } & Forward & GGGGACTTTGACTGGGGTGG \\
\hline & Reverse & AAGTAGACAAGATCAGTCCGGGTG \\
\hline \multirow[t]{2}{*}{ WNT5a } & Forward & TTTCTCCTTCGCCCAGGTTG \\
\hline & Reverse & GCGTACGTGAAGGCCGTCTC \\
\hline \multirow[t]{2}{*}{ FZD1 } & Forward & ACGGCGAACGGGGCATCTCC \\
\hline & Reverse & TGGGGTGCCTTTGTCGGACG \\
\hline \multirow[t]{2}{*}{ FZD2 } & Forward & СCCTGCCCCGCCTGCTGCTG \\
\hline & Reverse & GTAGCGCAGGAGCTCCGTCC \\
\hline \multirow[t]{2}{*}{ FZD7 } & Forward & CTGAGAACGCCGCTGCACTC \\
\hline & Reverse & CTGGCCACTGGAAGCCGAAC \\
\hline
\end{tabular}



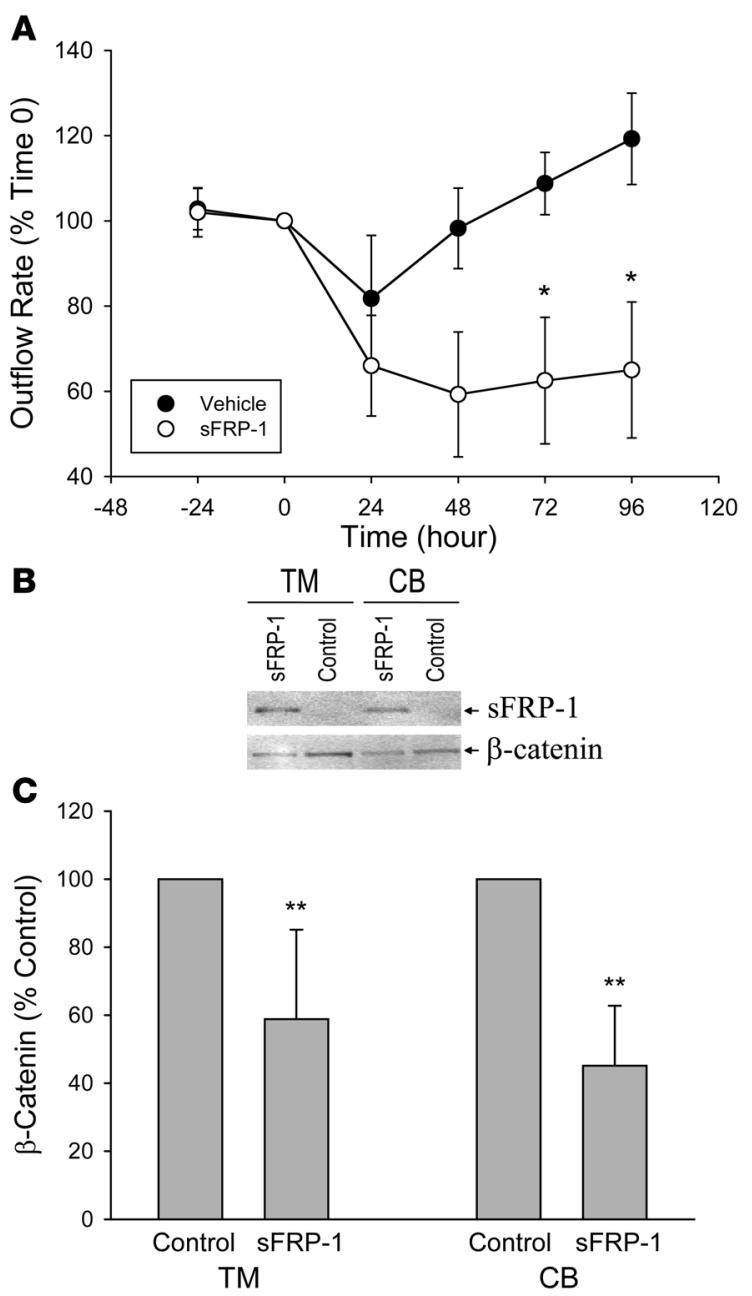

ings suggest that the TM contains a Wnt signaling system and further implies that sFRP-1 may alter TM functions. Indeed, we found a decrease in the aqueous outflow rate after sFRP-1 treatment of ex vivo perfused human eyes, which correlated with reduced $\beta$-catenin levels in the TM of the perfused tissues. In studies reported by others, nonspecific proteins (BSA, $\beta$-galactosidase, fetal bovine serum, or human serum) in much higher concentrations than the sFRP-1 concentration $(10 \mu \mathrm{g} / \mathrm{ml})$ used in this study, did not raise IOP of perfused human eyes (21). These observations, to our knowledge, are the first evidence of a functional canonical Wnt signaling pathway in the TM. They support a role for Wnt signaling in maintaining normal aqueous outflow through the TM and further suggest that perturbation of Wnt signaling in the TM caused the glaucoma associated phenotype of decreased aqueous outflow.

Results from the ex vivo perfusion study were substantiated by in vivo studies. Overexpression of human SFRP-1 in mouse eyes by intraocular injection of Ad5.sFRP-1 elevated IOP. The magnitude of the effect correlated with $s F R P 1$ expression, which in turn was dependent on the amount of viral vector injected. These results suggested that the adenovirus-mediated expression of human $S F R P 1$, which has $95 \%$ amino acid homology with mouse sFRP1, could interact with the mouse Wnt signaling pathway. A similar study reported that the mouse Wnt signaling was impaired by adenovirus mediated overexpression of bovine sFRP1, which has $95 \%$ homology

\section{Figure 3}

Effects of sFRP-1 on perfusion-cultured human eyes. (A) Effect of recombinant human sFRP-1 $(10 \mu \mathrm{g} / \mathrm{ml})$ on aqueous outflow rate. The treatment started from time $0 .{ }^{*} P<0.05$ versus same time point of the vehicle group (mean $\pm \mathrm{SEM} ; n=4$ ). There was no significant difference in basal flow rates between the 2 groups at time 0 . (B) Western blot analysis of SFRP-1 and $\beta$-catenin in TM and CB of perfused human eyes. (C) ELISA assessment of $\beta$-catenin levels in control and sFRP-1perfused TM and CB (mean \pm SEM, $n=4)$. ${ }^{* \star} P<0.01$.

with the mouse protein (22). Most importantly, the Ad5.sFRP-1induced increase in IOP was significantly diminished by topical ocular administration of a selective GSK-3 inhibitor. The drug effect lasted for at least 2 additional days after termination of treatment. It is interesting to note that the GSK-3 inhibitor only partially suppressed the Ad5.sFRP-1-induced ocular hypertension, which may be a result of less than optimal pharmacokinetics of the treatment. In addition, an alternative signaling pathway may be involved in the sFRP-1 effect. Regardless, these results argue that the canonical Wnt signaling pathway, in which GSK-3 and $\beta$-catenin are critical components, most likely plays an important role in maintaining normal IOP, and that increased expression of sFRP-1 alters this signaling pathway in the TM and leads to ocular hypertension.

We believe the discovery of sFRP-1 and associated Wnt signaling in the human TM is novel and intriguing. Wnt proteins are extracellular agents that bind to a variety of receptors to turn on several signaling pathways. Interaction with members of the Fzd family of seven-pass transmembrane molecules can activate phospholipase $C$ and calcium influx, which is mediated by the $G$ protein $\mathrm{G}_{\mathrm{q}}$. In addition, Wnt can also stimulate phosphodiesterase(s) and interfere with cyclic GMP metabolism in the cell via the activation of $\mathrm{G}_{\mathrm{t}}(23)$. Wnt/Fzd signaling also promotes cell motility and tissue polarity through mechanisms that involve Rho family small GTPases and downstream kinases such as ROCK and JNK (24). Our preliminary results suggest that these pathways are not prominent in the human TM cells (unpublished observations). Instead, our findings show that the canonical Wnt/ $\beta$-catenin pathway is operative in the TM. Activation of this pathway requires Wnt binding both to a Fzd and LDL receptor-related protein 5 or 6 (LRP5/6). Formation of this ternary complex leads to the disruption of a multiprotein assembly, including Axin, adenomatous polyposis coli (APC) tumor suppressor, GSK-3 $\beta$, and $\beta$-catenin, which functions to promote the phosphorylation and degradation of $\beta$-catenin. Consequently, stimulation of this signaling mechanism results in the accumulation of $\beta$-catenin in the cytoplasm and ultimately the nucleus, where it interacts with DNA-binding proteins of the T cell factor/lymphoid enhancer factor (TCF/LEF) family to turn on the expression of Wnt target genes (25). Binding of sFRP-1 directly to Wnts inhibits their activity, presumably by preventing their interaction with Fzds (18, $19,26)$. Recently, other sFRPs were shown to inhibit the proteolytic activity of tolloid metalloproteinases (27). This raises the possibility that sFRP-1 might have activities independent of Wnt regulation. At the present time, we are not able to conclusively confirm an inverse relationship between sFRP- 1 and $\beta$-catenin levels in human glaucoma TM samples or cultured human TM cells due to the complex interactions among multiple endogenously expressed Wnts and sFRPs. In addition, a large portion (50\%-60\%) of the $\beta$-catenin in the TM cells is associated with the plasma membrane (unpublished observations), probably via the formation of $\beta$-catenin/cadherin complexes, which further complicates assessment of the pool of 
A

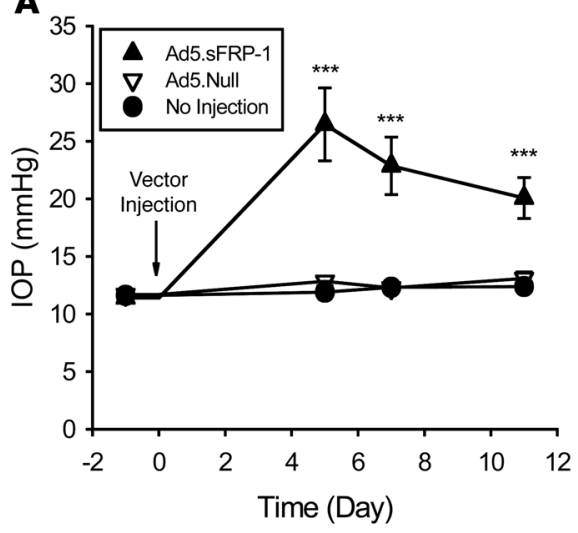

B

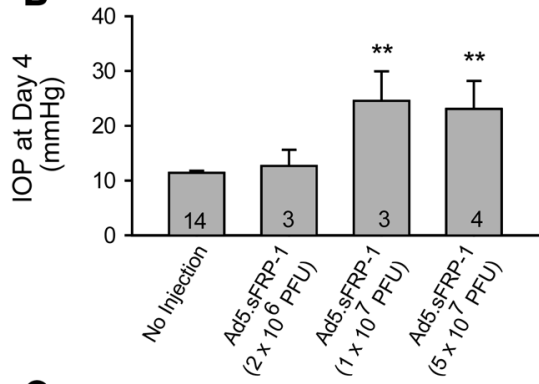

C

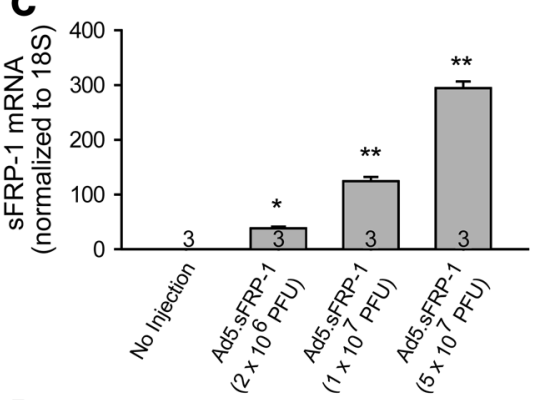

D

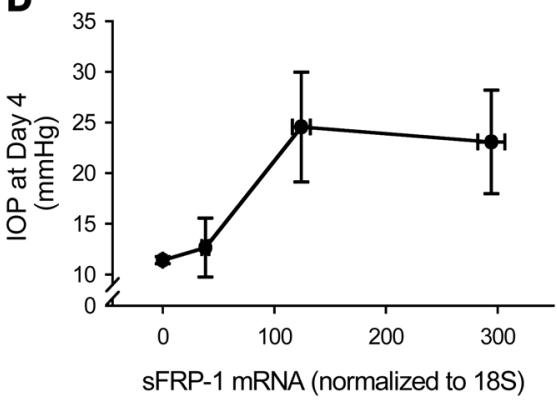

Figure 4

Effects of Ad5.sFRP-1 on mouse IOP and sFRP1 expression. (A) Ad5.sFRP1 $\left(3 \times 10^{7}\right.$ PFU/eye, $n=6)$ or Ad5.Null ( $3 \times 10^{7}$ PFU/eye, $n=6$ ) was injected intravitreally at day 0 . IOP was measured with the TonoLab rebound tonometer. (B) Mouse IOP at day 4 after intravitreal injection of Ad5.sFRP-1 $\left(2 \times 10^{6}, 1 \times 10^{7}\right.$, or $\left.5 \times 10^{7} \mathrm{PFU} / \mathrm{eye}\right)$. Sample sizes are indicated by the number at the base of each bar. (C) Expression of SFRP1 assayed by quantitative RT-PCR in mouse eyes injected with the vectors indicated in B at day 6 after injection. (D) Correlation between SFRP1 expression level and IOP in mice. Data are shown as mean \pm SEM. ${ }^{\star} P<0.05,{ }^{* \star} P<0.01,{ }^{* * \star} P<0.001$ versus "No injection" group by 1-way ANOVA then Bonferroni's test. unbound $\beta$-catenin available for canonical Wnt signaling. Nevertheless, we demonstrated that perfusion of human ocular tissue with sFRP-1 reduced the level of cytosolic $\beta$-catenin in both TM and $\mathrm{CB}$ tissues concomitant with a decrease in aqueous outflow facility. This finding is consistent with the presence of a functional, IOPregulating Wnt/ $\beta$-catenin pathway in the eye.

Wnt-dependent $\beta$-catenin signaling is highly conserved among species and has an important role in the development of flies, worms, and vertebrates from fish to mammals. Wnts affect the growth and differentiation of various organs and systems, including the CNS $(23,28)$, liver (29), and kidney (30). It is also implicated in carcinogenesis in the mammary gland (26), colon (31), lung (32), and stomach (33), among others (34). In the eye, the Wnt/Fzd signaling pathways are involved in various stages of ocular development and growth, such as the regulation of formation and size of the eye field, cell proliferation, polarity, connectivity, differentiation, and functional integrity, especially in the lens and retina. Mutations in components of Wnt signaling pathways may contribute to many ocular diseases, including exudative vitreoretinopathy, retinal degenerations, cataract, ocular tumors, and congenital ocular malformations (35). Interestingly, overexpression of sFRP-1 has been observed in Graves ophthalmopathy and is thought to contribute to adipogenesis in this context (36). Our findings in the current report indicate that inhibition of Wnt signaling is also involved in glaucoma, thus further expanding the list of Wnt connections to many normal and pathological conditions.
The involvement of Wnt signaling in glaucoma presents an interesting parallel to the involvement of TGF- $\beta$ in glaucoma (37-40). Both of these factors participate in the development and differentiation of various tissues and organs. For example, the early developmental events involved in germ-layer induction in the embryo require activation of both TGF- $\beta$ and Wnt (41). In murine mammary gland epithelial cells, combination treatment of TGF- $\beta$ and Wnt generates a unique gene expression pattern that cannot be predicted from single-ligand treatments (42). Moreover, the 2 signaling systems are tightly intertwined, such that TGF- $\beta$ stimulates the accumulation of $\beta$-catenin and LEF1 in human prostate cancer cells and keratinocytes (43), activates $\beta$-catenin mediated transcription in human dermal fibroblasts (44), and induces rapid nuclear translocation of $\beta$-catenin in mesenchymal stem cells (45). Similar interactions between these 2 signaling pathways may occur in the TM and contribute to the regulation of TM functions and thus IOP.

The molecular mechanisms associated with the regulation of TM functions are complex. We recently discovered that the biological effects of TGF- $\beta$ in the TM can be modulated by the bone morphogenic proteins (BMPs) and their antagonist gremlin (46). These findings highlight the intricate interrelationships among signaling pathways, because BMP and Wnt signals can interact to coordinate tissue development. For example, in the spinal cord, crosstalk between Wnt and BMP signaling controls the balance between proliferation and differentiation (28), and both signals coordinately organize the specification of dorsal neurons (47). For neural crest 


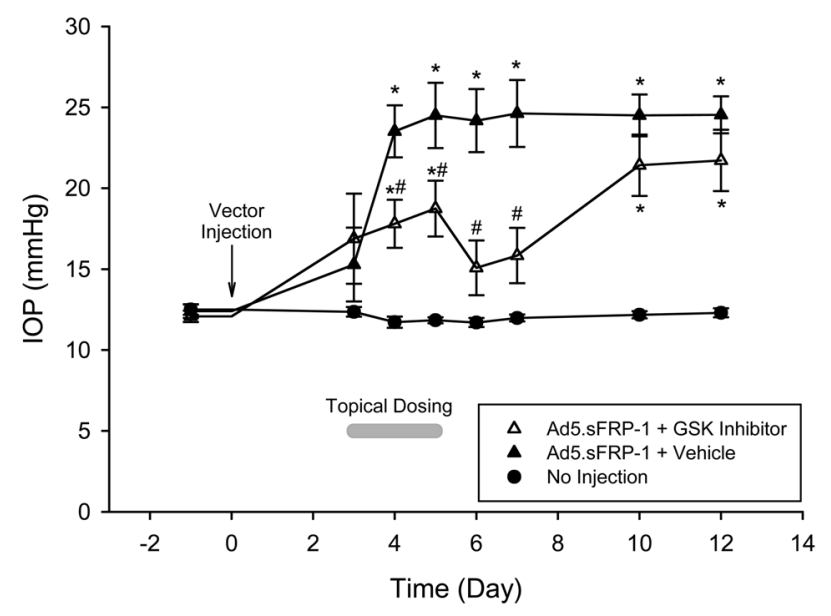

cells, BMP signals are involved in establishing a competency zone at the border of the neurectoderm, while subsequent Wnt signals induce cell differentiation (48). During ectopic bone formation, BMP-2 induces Wnt signaling, and $\beta$-catenin is required for both chondrogenesis and osteogenesis (49). In osteoblast progenitors, BMP-2 antagonizes Wnt by promoting an interaction between Smad1 and Dvl- 1 that restricts $\beta$-catenin activation (50). These interactions between BMP and Wnt, together with those between BMP and TGF- $\beta$, as well as TGF- $\beta$ and Wnt, impose a fascinating potential web of feedback and feed-forward checkpoints to regulate TM cell function, IOP, and glaucoma pathogenesis.

In summary, we have found that increased expression of sFRP-1 in glaucomatous TM may be responsible for the glaucoma phenotype of elevated IOP in humans. This discovery will lead to additional studies aiming to determine the prevalence of defects in the Wnt pathway in the glaucoma population, the primary cause of altered sFRP-1 expression, and the potential deficiency of other members of the WNT pathway involved in glaucoma. The identification of what we believe to be a novel pathogenesis mechanism and future understanding of the related signaling steps will certainly offer potential new disease intervening strategies, such as inhibition of GSK, for the treatment of ocular hypertension in glaucoma.

\section{Methods}

Human ocular tissues. All human donor eyes were obtained from the Central Florida Lions Eye and Tissue Bank. For RNA isolation, donor eyes less than 5 h post-mortem were bisected equatorially and preserved in RNAlater (Ambion) at the eye bank before shipment. The TM tissues were carefully dissected later and stored at $-80^{\circ} \mathrm{C}$ for subsequent RNA isolation (51). For protein extraction, TM tissues from donor eyes were dissected less than $24 \mathrm{~h}$ post-mortem and stored at $-80^{\circ} \mathrm{C}$ until used.

Culture of buman TM cells. Human TM cells were isolated and characterized as described previously $(52,53)$. Cell cultures were maintained in DMEM supplemented with 10\% FBS (Hyclone Laboratories), $2 \mathrm{mM}$ L-glutamine, penicillin (10,000 units/ml), and streptomycin $(10 \mu \mathrm{g} / \mathrm{ml})$ (Gibco BRL).

$R N A$ extraction and cDNA preparation. Total RNA was extracted from cultured TM cells or from RNAlater preserved TM tissues using a commercial kit, RNAqueous-4 PCR (Ambion) or ToTALLY RNA (Ambion), according to the manufacturer's instructions (51). RNA quality was assessed by agarose gel electrophoresis or by analysis using the 2100 Bioanalyzer (Agilent). cDNA was synthesized using MultiScribe reverse transcriptase and random hexamers (PE Applied Biosystems). PCR was performed with

\section{Figure 5}

Effect of GSK inhibitor on sFRP1-induced ocular hypertension in mice. After intraocular injection of Ad5.sFRP-1 (3 $\times 10^{7}$ PFU/eye) at day 0 , twice daily topical ocular administrations of a GSK inhibitor, Compound 12 ( $1 \% \mathrm{wt} / \mathrm{vol}$ suspension), or vehicle were performed on days 3,4 , and 5 (gray horizontal bar). ${ }^{*} P<0.05$ versus the "No injection" group; $\# P<0.05$ versus the "Ad5.sFRP-1 + Vehicle" group by 1 -way ANOVA then Bonferroni's test (mean \pm SEM; $n=10$ ).

GAPDH primers (forward, 5'-CCATGGAGAAGGCTGGGG-3'; reverse: 5'CAAAGTTGTCATGGATGACC-3') to evaluate cDNA quality.

$R D D$. RDD was performed using an mRNA differential display system, RNAimage, according to the manufacturer's instructions (GenHunter). Briefly, RNA from normal TM cells (NTM70A) and glaucomatous TM cells (GTM29C) was reverse transcribed using oligonucleotide primers H-T11M (where M may be A, C, or G), deoxynucleotide triphosphate, and Moloney murine leukemia virus reverse transcriptase and incubated for $60 \mathrm{~min}$ at $37^{\circ} \mathrm{C}$. The cDNAs were amplified by PCR by adding the reverse transcriptase reaction to a PCR mix, containing H-AP1, an arbitrary 10-mer primer (5'-AAGCTTGATTGCC-3'), a corresponding H-T11A primer (5'AAGGTTTTTTTTTTTA-3'), deoxynucleotide triphosphates, $\alpha^{33} \mathrm{P}$-dATP, and AmpliTaq DNA Polymerase (Applied Biosystems). Each sample was amplified and subjected to electrophoresis in duplicate. The PCR products were denatured, diluted with a running buffer, and separated on a $6 \%$ polyacrylamide denaturing gel using a Sequi-Gen GT nucleic acid electrophoresis cell (BioRad). The gels were blotted on $3 \mathrm{M}$ filter paper, covered with plastic wrap, and exposed to autoradiography overnight at $-80^{\circ} \mathrm{C}$. Differentially expressed cDNA bands were cut out of the gels, boiled in double-distilled water, precipitated by ethanol, and resuspended in water. This cDNA was used as template for PCR reamplification as described above but without radioactive nucleotide. The reamplified PCR products were purified by agarose gel and directly sequenced by an automated ABI sequencer (Perkin-Elmer).

Microarray experiment. Gene expression profiling was conducted using Affymetrix U133A/B Arrays for TM tissues or U133 Plus 2.0 Array (Affymetrix Inc.) for cultured TM cells. TM tissue RNA was extracted individually and pooled from 13 normal donor tissues (average donor age was 81.7 years, ranging from 70-92 years), and TM cell RNA was extracted from a normal cultured TM cell line (NTM153-00). Ten micrograms of total RNA was used for each microarray study. Synthesis of cDNA and biotin-labeled antisense cRNA, target hybridization, washing, staining, and scanning probe arrays were conducted at the University of Iowa DNA Facility according to the Affymetrix Genechip Expression Analysis Technical Manual. The microarray gene expression was analyzed with the Affymetrix Microarray Suite software.

Real-time quantitative PCR. Real-time quantitative PCR was performed using the ABI Prism 7700 Sequence Detection System according to the manufacturer's instructions (PE Applied Biosystems). Typical multiplex PCR reaction mixtures consisted of 1X TaqMan Universal PCR Master Mix (PE Applied Biosystems), cDNA from $2.5 \mathrm{ng}$ of total RNA, and the specified primer (200 nM), probe $(100 \mathrm{nM})$, and $\beta$-actin or $18 \mathrm{~S}$ ribosomal RNA control (PE Applied Biosystems) in a final volume of $25 \mu \mathrm{l}$. Thermal cycling conditions were $50^{\circ} \mathrm{C}$ for $2 \mathrm{~min}$ and $95^{\circ} \mathrm{C}$ for $10 \mathrm{~min}$, followed by 40 cycles at $95^{\circ} \mathrm{C}$ for $15 \mathrm{~s}$ and $60^{\circ} \mathrm{C}$ for $1 \mathrm{~min}$. Relative RNA concentrations were determined by comparison to a standard curve generated by different dilutions of TM cell cDNA (54). Sequences of primers and probes used in this study are described in Table 2.

Western immunoblotting. For sFRP- 1 and $\beta$-catenin analysis, TM and CB tissues were dissected from the perfused human anterior segments and homogenized in M-Per buffer (Pierce). Protein concentration in each sample was determined using the BCA Protein reagent (Pierce). Proteins $(10 \mu \mathrm{g})$ were separated on SDS-PAGE (NuPAGE Bis-Tris system; Invitrogen), transferred to PVDF membranes (Invitrogen), blocked with $3 \%$ gelatin, and probed with a mouse 
monoclonal antibody for human $\beta$-catenin (Transduction Laboratories) and a sheep anti-mouse IgG-HRP secondary antibody (Amersham). Visualization was performed either by chemiluminescence using ECL Plus (Amersham) and exposure to BioMax MR X-ray film (Eastman Kodak) or by scanning on a Storm 840 Phosphorimager (Molecular Dynamics). Quantitation was done using ImageQuant software (Molecular Dynamics). The $\beta$-catenin blot was then reprobed for SFRP-1 analysis in a similar manner to $\beta$-catenin analysis, but a protein $\mathrm{G}$-purified rabbit polyclonal antiserum raised against human sFRP-1 (18) and an anti-rabbit IgG secondary antibody conjugated to horseradish peroxidase (donkey anti-rabbit; Amersham) were used.

$\beta$-catenin ELISA. A sandwich-type ELISA was constructed, using a mouse monoclonal antibody to $\beta$-catenin (Transduction Laboratories) as the capture antibody and a rabbit polyclonal $\beta$-catenin antibody (Santa Cruz Biotechnology) along with donkey anti-rabbit IgG-HRP (Amersham) for detection. Washing between incubation steps was with PBS plus $0.1 \%$ Triton X-100 (PBST; Sigma-Aldrich). Wells of microtiter plates were coated with $50 \mathrm{ng}$ of monoclonal anti- $\beta$-catenin in $100 \mu \mathrm{l}$ of $0.05 \mathrm{M}$ carbonate-bicarbonate buffer, pH 9.6 (Sigma-Aldrich), and incubated overnight at $4^{\circ} \mathrm{C}$. Blocking of nonspecific binding was done with $300 \mu \mathrm{l}$ of $0.2 \%$ (wt/vol) protease-free BSA (Sigma-Aldrich) in $0.05 \mathrm{M}$ carbonate-bicarbonate buffer. Cell samples were diluted in $1 \%(\mathrm{wt} / \mathrm{vol})$ protease-free BSA in PBST, and $50 \mu \mathrm{l}$ was added to the wells and incubated for $1 \mathrm{~h}$. The second $\beta$-catenin antibody was used at 1:100 dilution, and the detection antibody was diluted 1:1,000 in 1\% BSA/PBST and added at $100 \mu \mathrm{l} /$ well. Substrate, 3,3',3,5'-tetramethylbenzidine (TMB, $100 \mu \mathrm{l} /$ well; Sigma-Aldrich), was added and incubated for $30 \mathrm{~min}$, and the reaction stopped with $50 \mu \mathrm{l}$ of $0.5 \mathrm{M} \mathrm{H}_{2} \mathrm{SO}_{4}$. Absorbance was measured at $450 \mathrm{~nm}$ using $570 \mathrm{~nm}$ for background correction.

sFRP-1 ELISA. Goat polyclonal anti-human sFRP-1 (R\&D Systems), $50 \mathrm{ng} /$ well, was used as the capture antibody to create a sandwich-type ELISA, employing the same buffers, detection reagents, and general procedures as used for the $\beta$-catenin ELISA. The second sFRP- 1 antibody was a polyclonal anti-human sFRP-1 generated in rabbits as follows. The peptide sequence, ${ }^{288}$ DKKNKENFKNFMKKMKNHEC ${ }^{306}$, was synthesized to $93 \%$ purity using f-MOC chemistry, and its mass was verified by mass spectrometry (SigmaAldrich). The peptide was conjugated to keyhole limpet antigen through the terminal cysteine and injected into 2 rabbits at 2 -week intervals using complete and incomplete Freund adjuvant. Serum was collected at 3-week intervals. Total IgG was affinity purified by binding to chimeric Protein A/G Agarose (Pierce Chemical Company). After elution of the antibodies and dialysis against standard PBS, glycerol was added to $10 \% \mathrm{vol} / \mathrm{vol}$. Aliquots were frozen in liquid nitrogen and stored at $-80^{\circ} \mathrm{C}$. This antibody was used at $1: 100$ dilution, and detection was with donkey anti-rabbit IgG-HRP (Amersham).

Perfusion-cultured human eyes. Human anterior segments were set up for perfusion culture as described previously (55-57). Human donor eyes obtained from regional eye banks were used within $24 \mathrm{~h}$ of death. Eyes were equatorially bisected with the lens, iris, and vitreous removed. The anterior segment was then mounted in a sterile custom-made Plexiglass culture dish and sealed with a Plexiglas O-ring. The eyes were perfused with DMEM containing L-glutamine, penicillin, streptomycin, and gentamycin (Gibco$\mathrm{BRL}$ ) at a constant hydrostatic pressure of $12.5 \mathrm{mmHg}$. Perfusion rate was measured by daily weighing of the inflow reservoir, assuming the density of the perfusate as $1 \mathrm{~g} / \mathrm{ml}$. One eye of each pair was perfused with medium containing recombinant human sFRP-1 $(10 \mu \mathrm{g} / \mathrm{ml})$, a concentration shown to have an optimal inhibitory effect on Wnt signaling (19), while the contralateral eye was treated with vehicle. At the end of the culture period, TM tissue of each eye was divided into 4 quadrants along the circumference and carefully dissected. Two quadrants were fixed and examined by transmission electron microscopy to determine tissue viability. Only data derived from viable tissues were included for analysis $(55,56)$. Based on this criterion, results from 1 pair of eyes (out of 5) were discarded in the cur- rent study. Remaining TM and CB tissues were carefully dissected, proteins extracted, and immunoblotted for sFRP-1 and $\beta$-catenin levels.

Construction of Ad5.sFRP-1 viral vector. Ad5.sFRP-1 viral vector was customconstructed by Qbiogene. Briefly, the 1,067-bp human sFRP-1 insert (NCBI nucleotide sequence number AF056087) in pcDNA3.1 plasmid DNA, obtained from ATCC, was cut using Not I and Xbal and cloned into the pAdenovatorCMV5(CuO)-IRES-GFP transfer vector. Positive expression of the 35.4-kDa protein was confirmed by Western blot. Viral plaques were generated using the transfer plasmid and the pAdenoVator $\Delta \mathrm{E} 1 / \mathrm{E} 3$ viral plasmid DNA. Plaques were picked and amplified in 293 cells for protein expression detection by Western blotting. All clones tested were positive for the protein of interest. One clone was amplified in $10^{9} 293 \mathrm{CymR}$ cells. Following freeze/thaw cycles, the adenoviruses present in the supernatant were purified on 2 successive $\mathrm{CsCl}_{2}$ gradients and dialyzed against sterile $20 \mathrm{mM}$ Tris $\mathrm{pH}$ 8.0, $25 \mathrm{mM} \mathrm{NaCl}$, and $2.5 \%$ glycerol. The Ad5.sFRP-1 was titered by optical density and plaque assay, and aliquots of the virus were stored at $-80^{\circ} \mathrm{C}$ until use. Control Ad5.GFP (Ad5.CMV5-GFP) and Ad5.Null were also obtained from Qbiogene.

Intravitreal injection and IOP measurement. All animal procedures performed in this study complied with the ARVO Statement for the Use of Animals in Ophthalmic and Vision Research and were approved by the Alcon Independent Animal Care and Use Committee. Adult male BALB/c mice of 20-35 g (The Jackson Laboratory) were housed in transparent plastic rodent boxes under 12-h light/dark cycle with lights on starting at $6 \mathrm{AM}$. Mouse chow and water were available ad libitum. For intravitreal injections, the animals were anesthetized with a mouse anesthesia cocktail (intraperitoneal injection of acepromazine [ $1.8 \mathrm{mg} / \mathrm{kg}$ ], ketamine [73 mg/kg], and xylazine $[1.8 \mathrm{mg} / \mathrm{kg}])$. Adenoviral vectors $\left(2 \times 10^{6}\right.$ to $5 \times 10^{7} \mathrm{PFU} /$ eye $)$ were injected intravitreally in a volume of $2 \mu$ into a randomly-selected eye of each animal. The contralateral eye was not injected. IOP measurements on conscious animals were performed in a masked fashion using the TonoLab rebound tonometer (Colonial Medical Supply) as described (58). At day 6 after injection, mouse eyes were enucleated and total RNA extracted for use in detecting viral vector mediated sFRP-1 expression.

GSK inhibitor. To evaluate the effect of a selective GSK inhibitor, [N-(5-phenyl-1H-pyrazolo[3,4-C]pyridazino-3 yl)-4-morpholine butanamide] Compound 12, was synthesized according to Witherington, et al. (20). It was formulated as a stable suspension, which was comprised of Compound 12 (1\% wt/vol), $\mathrm{Na}_{2} \mathrm{PO}_{4} \cdot 12 \mathrm{H}_{2} \mathrm{O}(0.5 \%), \mathrm{NaCl}(0.75 \%), \mathrm{Na}_{2}$ EDTA (0.01\%), hydroxypropyl methylcellulose $(0.5 \%)$, polysorbate $80(0.05 \%), \mathrm{pH}$ to 7.4. At days 3 to 5 after intraocular injection of Ad5.sFRP- $1\left(5 \times 10^{7} \mathrm{pfu} /\right.$ eye $)$, $5 \mu \mathrm{l}$ of the drug suspension or vehicle (formulation containing all ingredients except Compound 12) was administered onto the cornea twice daily.

Statistics. For comparisons between 2 groups, the unpaired Student's $t$ test was used. For comparisons among 3 or more groups, 1-way ANOVA followed by Bonferroni's test was applied. A value of $P<0.05$ represents statistical significance.

\section{Acknowledgments}

This work was supported in part by the Intramural Research Program of the National Cancer Institute, NIH and by Alcon Research Ltd. The authors thank Paula Billman for human tissue procurement and Debbie Lane and Robin Chambers for culturing human TM cells.

Received for publication September 7, 2007, and accepted in revised form December 19, 2007.

Address correspondence to: Abbot F. Clark, Glaucoma Research, R2-41, Alcon Research Ltd., 6201 South Freeway, Fort Worth, Texas 76134, USA. Phone: (817) 551-4909; Fax: (817) 568-7645; E-mail: abe.clark@alconlabs.com. 
1. Quigley, H.A. 1996. Number of people with glaucoma worldwide. Br. J. Ophthalmol. 80:389-393.

2. Quigley, H.A. 1998. The search for glaucoma genes implications for pathogenesis and disease detection. N. Engl. J. Med. 338:1063-1064.

3. Quigley, H.A. 1993. Open-angle glaucoma. N. Engl. J. Med. 328:1097-1106.

4. Kass, M.A., et al. 2002. The Ocular Hypertension Treatment Study: a randomized trial determines that topical ocular hypotensive medication delays or prevents the onset of primary open-angle glaucoma. Arch. Ophthalmol. 120:701-713; discussion 829-830.

5. The AGIS Investigators. 2000. The Advanced Glaucoma Intervention Study (AGIS): 7. The relationship between control of intraocular pressure and visual field deterioration. The AGIS Investigators. Am. J. Ophthalmol. 130:429-440.

6. Heijl, A., et al. 2002. Reduction of intraocular pressure and glaucoma progression: results from the Early Manifest Glaucoma Trial. Arch. Ophthalmol. 120:1268-1279.

7. Leske, M.C., Connell, A.M., Wu, S.Y., Hyman, L.G., and Schachat, A.P. 1995. Risk factors for openangle glaucoma. The Barbados Eye Study. Arch. Ophthalmol. 113:918-924.

8. Sommer, A., et al. 1991. Relationship between intraocular pressure and primary open angle glaucoma among white and black Americans. The Baltimore Eye Survey. Arch. Ophthalmol. 109:1090-1095.

9. Gordon, M.O., et al. 2002. The Ocular Hypertension Treatment Study: baseline factors that predict the onset of primary open-angle glaucoma. Arch. Ophthalmol. 120:714-720; discussion 829-830.

10. Nishimura, D.Y., et al. 1998. The forkhead transcription factor gene FKHL7 is responsible for glaucoma phenotypes which map to $6 \mathrm{p} 25$. Nat. Genet. 19:140-147.

11. Fingert, J.H., et al. 1999. Analysis of myocilin mutations in 1703 glaucoma patients from five different populations. Hum. Mol. Genet. 8:899-905.

12. Libby, R.T., Gould, D.B., Anderson, M.G., and John, S.W. 2005. Complex genetics of glaucoma susceptibility. Annu. Rev. Genomics Hum. Genet. 6:15-44.

13. Liton, P.B., Luna, C., Challa, P., Epstein, D.L., and Gonzalez, P. 2006. Genome-wide expression profile of human trabecular meshwork cultured cells, nonglaucomatous and primary open angle glaucoma tissue. Mol. Vis. 12:774-790.

14. Wang, N., Chintala, S.K., Fini, M.E., and Schuman, J.S. 2001. Activation of a tissue-specific stress response in the aqueous outflow pathway of the eye defines the glaucoma disease phenotype. Nat. Med. 7:304-309.

15. Bhattacharya, S.K., Peachey, N.S., and Crabb, J.W. 2005. Cochlin and glaucoma: a mini-review. Vis. Neurosci. 22:605-613.

16. Bhattacharya, S.K., et al. 2005. Proteomics reveal Cochlin deposits associated with glaucomatous trabecular meshwork. J. Biol. Chem. 280:6080-6084.

17. Shepard, A.R., et al. 2007. Glaucoma-causing myocilin mutants require the Peroxisomal targeting signal-1 receptor (PTS1R) to elevate intraocular pressure. Hum. Mol. Genet. 16:609-617.

18. Finch, P.W., et al. 1997. Purification and molecular cloning of a secreted, Frizzled-related antagonist of Wnt action. Proc. Natl. Acad. Sci. U. S. A. 94:6770-6775

19. Uren, A., et al. 2000. Secreted frizzled-related protein- 1 binds directly to Wingless and is a biphasic modulator of Wnt signaling. J. Biol. Chem. 275:4374-4382.

20. Witherington, J., et al. 2003. 5-aryl-pyrazolo[3,4b]pyridazines: potent inhibitors of glycogen synthase kinase-3 (GSK-3). Bioorg. Med. Chem. Lett. 13:1581-1584.

21. Fautsch, M.P., Bahler, C.K., Jewison, D.J., and
Johnson, D.H. 2000. Recombinant TIGR/MYOC increases outflow resistance in the human anterior segment. Invest. Ophthalmol. Vis. Sci. 41:4163-4168.

22. Ezan, J., et al. 2004. FrzA/sFRP-1, a secreted antagonist of the Wnt-Frizzled pathway, controls vascular cell proliferation in vitro and in vivo. Cardiovasc. Res. 63:731-738.

23. Partanen, J. 2007. FGF signalling pathways in development of the midbrain and anterior hindbrain. J. Neurochem. 101:1185-1193.

24. Seifert, J.R., and Mlodzik, M. 2007. Frizzled/PCP signalling: a conserved mechanism regulating cell polarity and directed motility. Nat. Rev. Genet. 8:126-138.

25. Clevers, H. 2006. Wnt/beta-catenin signaling in development and disease. Cell. 127:469-480.

26. Turashvili, G., Bouchal, J., Burkadze, G., and Kolar, Z. 2006. Wnt signaling pathway in mammary gland development and carcinogenesis. Pathobiology. 73:213-223.

27. Lee, H.X., Ambrosio, A.L., Reversade, B., and De Robertis, E.M. 2006. Embryonic dorsal-ventral signaling: secreted frizzled-related proteins as inhibitors of tolloid proteinases. Cell. 124:147-159.

28. Ille, F., et al. 2006. Wnt/BMP signal integration regulates the balance between proliferation and differentiation of neuroepithelial cells in the dorsal spinal cord. Dev. Biol. 304:394-408.

29. Apte, U., et al. 2007. beta-Catenin is critical for early postnatal liver growth. Am. J. Physiol. Gastrointest. Liver Physiol. 292:G1578-G1585.

30. Kuure, S., Popsueva, A., Jakobson, M., Sainio, K., and Sariola, H. 2007. Glycogen synthase kinase-3 inactivation and stabilization of beta-catenin induce nephron differentiation in isolated mouse and rat kidney mesenchymes. J. Am. Soc. Nephrol. 18:1130-1139.

31. Prall, F., Weirich, V., and Ostwald, C. 2007. Phenotypes of invasion in sporadic colorectal carcinomas related to aberrations of the adenomatous polyposis coli (APC) gene. Histopathology. 50:318-330.

32. Coffin, C.M., Hornick, J.L., Zhou, H., and Fletcher, C.D. 2007. Gardner fibroma: a clinicopathologic and immunohistochemical analysis of 45 patients with 57 fibromas. Am. J. Surg. Pathol. 31:410-416.

33. Nojima, M., et al. 2007. Frequent epigenetic inac tivation of SFRP genes and constitutive activation of Wnt signaling in gastric cancer. Oncogene. 26:4699-4713

34. Rubin, J.S., Barshishat-Kupper, M., Feroze-Merzoug, F., and Xi, Z.F. 2006. Secreted WNT antagonists as tumor suppressors: pro and con. Front. Biosci. 11:2093-2105.

35. de Iongh, R.U., Abud, H.E., and Hime, G.R. 2006 WNT/Frizzled signaling in eye development and disease. Front. Biosci. 11:2442-2464.

36. Kumar, S., Leontovich, A., Coenen, M.J., and Bahn, R.S. 2005. Gene expression profiling of orbital adipose tissue from patients with Graves' ophthalmopathy: a potential role for secreted frizzledrelated protein-1 in orbital adipogenesis. J. Clin. Endocrinol. Metab. 90:4730-4735.

37. Tripathi, R.C., Li, J., Chan, W.F., and Tripathi, B.J. 1994. Aqueous humor in glaucomatous eyes contains an increased level of TGF-beta 2. Exp. Eye Res. 59:723-727.

38. Inatani, M., et al. 2001. Transforming growth factor-beta 2 levels in aqueous humor of glaucomatous eyes. Graefes Arch. Clin. Exp. Ophthalmol. 239:109-113.

39. Picht, G., Welge-Luessen, U., Grehn, F., and LutjenDrecoll, E. 2001. Transforming growth factor beta 2 levels in the aqueous humor in different types of glaucoma and the relation to filtering bleb development. Graefes Arch. Clin. Exp. Ophthalmol. 239:199-207.

40. Yamamoto, N., Itonaga, K., Marunouchi, T., and Majima, K. 2005. Concentration of transforming growth factor beta2 in aqueous humor. Ophthalmic Res. 37:29-33.

41. Gadue, P., Huber, T.L., Paddison, P.J., and Keller, G.M. 2006. Wnt and TGF-beta signaling are required for the induction of an in vitro model of primitive streak formation using embryonic stem cells. Proc. Natl. Acad. Sci. U. S. A. 103:16806-16811.

42. Labbé, E., et al. 2007. Transcriptional cooperation between the transforming growth factor-beta and Wnt pathways in mammary and intestinal tumorigenesis. Cancer Res. 67:75-84.

43. Edlund, S., et al. 2005. Interaction between Smad7 and beta-catenin: importance for transforming growth factor beta-induced apoptosis. Mol. Cell. Biol. 25:1475-1488.

44. Sato, M. 2006. Upregulation of the Wnt/betacatenin pathway induced by transforming growth factor-beta in hypertrophic scars and keloids. Acta Derm. Venereol. 86:300-307.

45. Jian, H., et al. 2006. Smad3-dependent nuclear translocation of beta-catenin is required for TGFbeta1-induced proliferation of bone marrowderived adult human mesenchymal stem cells. Genes Dev. 20:666-674.

46. Wordinger, R.J., et al. 2007. Effects of TGF-beta2, BMP-4, and gremlin in the trabecular meshwork: implications for glaucoma. Invest. Ophthalmol. Vis. Sci. 48:1191-1200.

47. Zechner, D., et al. 2007. Bmp and Wnt/beta-catenin signals control expression of the transcription factor Olig3 and the specification of spinal cord neurons. Dev. Biol. 303:181-190.

48. Raible, D.W. 2006. Development of the neural crest: achieving specificity in regulatory pathways. Curr. Opin. Cell Biol. 18:698-703.

49. Chen, Y., et al. 2007. Beta-catenin signaling pathway is crucial for bone morphogenetic protein 2 to induce new bone formation. J. Biol. Chem. 282:526-533.

50. Liu, Z., Tang, Y., Qiu, T., Cao, X., and Clemens, T.L. 2006. A dishevelled-1/Smad 1 interaction couples WNT and bone morphogenetic protein signaling pathways in uncommitted bone marrow stromal cells. J. Biol. Chem. 281:17156-17163.

51. Wang, W.H., et al. 2001. Optimal procedure for extracting RNA from human ocular tissues and expression profiling of the congenital glaucoma gene FOXC1 using quantitative RT-PCR. Mol. Vis. 7:89-94.

52. Steely, H.T., et al. 1992. The effects of dexamethasone on fibronectin expression in cultured human trabecular meshwork cells. Invest. Ophthalmol. Vis. Sci. 33:2242-2250.

53. Clark, A.F., et al. 1994. Glucocorticoid-induced formation of cross-linked actin networks in cultured human trabecular meshwork cells. Invest. Ophthalmol. Vis. Sci. 35:281-294.

54. Shepard, A.R., et al. 2001. Delayed secondary glucocorticoid responsiveness of MYOC in human trabecular meshwork cells. Invest. Ophthalmol. Vis. Sci. 42:3173-3181.

55. Pang, I.H., McCartney, M.D., Steely, H.T., and Clark, A.F. 2000. Human ocular perfusion organ culture: a versatile ex vivo model for glaucoma research. J. Glaucoma. 9:468-479.

56. Clark, A.F., Wilson, K., de Kater, A.W., Allingham, R.R., and McCartney, M.D. 1995. Dexamethasoneinduced ocular hypertension in perfusion-cultured human eyes. Invest. Ophthalmol. Vis. Sci. 36:478-489.

57. Tschumper, R.C., Johnson, D.H., Bradley, J.M., and Acott, T.S. 1990. Glycosaminoglycans of human trabecular meshwork in perfusion organ culture. Curr. Eye Res. 9:363-369.

58. Wang, W.H., Millar, J.C., Pang, I.H., Wax, M.B., and Clark,A.F. 2005. Noninvasive measurement of rodent intraocular pressure with a rebound tonometer. Invest. Ophthalmol. Vis. Sci. 46:4617-4621. 